\title{
Viewpoint
}

\section{Sleeping more as a way to lose weight}

\author{
M. Sivak
}

The University of Michigan, Transportation Research Institute, 2901 Baxter Road, Ann Arbor, MI, USA

Received 5 January 2006; revised 20 February 2006; accepted 21 February 2006

Address for correspondence: M Sivak, The

University of Michigan, Transportation

Research Institute, 2901 Baxter Road, Ann

Arbor, MI 48109-2150, USA. E-mail:

sivak@umich.edu

\begin{abstract}
Summary
Caloric consumption in a society with readily available food is likely to be approximately proportional to the number of hours of being awake. Thus, replacing $1 \mathrm{~h}$ of inactive wakefulness (e.g. watching TV), with sleeping is likely to result in a substantial reduction in caloric intake. Calculations are presented to illustrate the possible benefits of such a switch on weight reduction.
\end{abstract}

Keywords: Food intake, sleep, TV watching, weight.

obesity reviews (2006) 7, 295-296
Two recent articles $(1,2)$ have suggested that the levels of the hormones leptin and ghrelin mediate an association between lack of sleep and weight gain. Specifically, these two studies have shown that a decrease in the amount of sleep was associated with a decrease in leptin and an increase in ghrelin. In turn, the directions of these changes are consistent with the postulated appetite-control mechanism, in which appetite is inversely related to the level of leptin and directly related to the level of ghrelin $(3,4)$.

Complicating the story are two aspects of the data by Taheri et al. (2). First, this study found a non-monotonic relationship between the average amount of reported nightly sleep and the body mass index. (The lowest body mass was associated with an intermediate amount of sleep.) However, it is possible that the obtained non-monotonic relationship is a consequence of sleep apnoea being associated with obesity (5). Obese people, because of their breathing difficulties during sleep, might average less deep sleep (6), and thus they may require a longer duration of sleep.

A second and more serious concern is that the correlation coefficients obtained by Taheri et al. (2) between the levels of leptin and ghrelin, and body mass index, although statistically significant (because of the large number of cases - 1017 and 856 respectively), were low. Consequently, the amounts of variance in body mass accounted for were very low: $3 \%$ for leptin and $1 \%$ for ghrelin. In other words,
$96 \%$ of the variance in body mass was not accounted for by the levels of leptin and ghrelin.

Thus, leptin and ghrelin [in addition to other hormones, such as cortisol and thyrotropin (7)] may turn out to be only a part of the story. There is another possible (non-hormonal) connection between sleep and weight, and this behavioural connection may provide a practical weight-reduction option. The basic point is that in a society with readily available food (here 'food' includes drinks as well), the longer we are awake, the more we are likely to consume. Thus, sleeping more will likely reduce caloric intake.

Caloric consumption in a society with readily available food is likely to be approximately proportional to the number of hours of being awake. By replacing $1 \mathrm{~h}$ of being awake (say, of watching TV) by sleeping, we forgo a significant consumption of food because of the resulting reduction in the opportunity to eat. Let's consider the following two scenarios.

The first scenario involves $7 \mathrm{~h}$ of sleeping, $17 \mathrm{~h}$ of being awake, and an intake of 2500 calories. This translates to 147 calories per hour (2500/17).

The second scenario involves $8 \mathrm{~h}$ of sleeping and $16 \mathrm{~h}$ of being awake. By being awake $1 \mathrm{~h}$ less, we are prone to consuming 147 fewer calories per day (a new total of 2353), for a reduction of about $6 \%$. (The proportional consumption per hour might actually be conservative in the 
case of replacing watching TV with sleeping, because watching TV is often accompanied by consumption of high-calorie snacks.)

A $6 \%$ reduction would apply regardless of the baseline level of calorie consumption, as long as the baseline level of being awake remains at $17 \mathrm{~h}(1 / 17=6 \%)$. For example, if the baseline consumption were 2000 calories, then by sleeping 8 vs. 7 h, one would save about 118 calories $(2000 / 17)$ or about $6 \%$. If the baseline level of being awake were higher, the benefits would be slightly lower (for $18 \mathrm{~h}$ it would be $1 / 18$ instead of $1 / 17)$; conversely, if the baseline were lower, the benefits would be slightly greater (for $16 \mathrm{~h}$ it would be $1 / 16$ instead of $1 / 17$ ).

The above-derived caloric reductions need to be corrected for by the differential calorie expenditures during sleep as opposed to sitting and watching TV. However, sleeping consumes only about $10 \%$ fewer calories than sitting and watching TV - about 81 vs. 90 calories per hour, depending on one's weight (8). Thus, in the above example, the net saving in calories would be 138 (147-9).

How does this translate into pounds of body weight? There are about 7700 calories per kilogram of body fat (9). Thus, replacing $1 \mathrm{~h}$ of TV watching with sleeping in the above example is predicted to result in a body-weight reduction of $1 \mathrm{~kg}$ in about 56 days (7700/138), or about $6.5 \mathrm{~kg}$ per year $(138 \times 365 \div 7700)$.

It is postulated in this paper that lack of sleep is an independent factor in obesity causation and not only an indirect consequence of an unhealthy lifestyle. However, direct evidence for the causative link does not yet exist.

Sleeping more is not proposed as a universal solution to obesity. For example, it is unlikely to apply to those overweight people who already sleep more than the generally recommended $8 \mathrm{~h}$ a night. Furthermore, for some people sleeping more cannot be achieved without therapeutic intervention. However, to the extent that a large proportion of the population is both overweight and voluntarily sleep deprived, replacing some sedentary activity with sleeping might offer a practical behavioural solution for a large segment of the overweight population.

\section{Conflict of Interest Statement}

No conflict of interest was declared.

\section{References}

1. Spiegel K, Tasali E, Penev P, Van Cauter E. Sleep curtailment in healthy men is associated with decreased leptin levels, elevated ghrelin levels, and increased hunger and appetite. Ann Intern Med 2004; 141: 846-850.

2. Taheri S, Lin L, Austin D, Young T, Mignot E. Short sleep duration is associated with reduced leptin, elevated ghrelin, and increased body mass index. PLoS Med 2004; 1: 210-217.

3. Chin-Chance C, Polonsky KS, Schoeller DA. Twenty-four-hour leptin levels respond to cumulative short-term energy imbalance and predict subsequent intake. J Clin Endocrinol Metab 2000; 85: 2685-2691.

4. van der Lely AJ, Tschop M, Heiman ML, Ghigo E. Biological, physiological, pathophysiological, and pharmacological aspects of ghrelin. Endocr Rev 2004; 25: 426-457.

5. Young T, Palta M, Dempsey J, Skatrud J, Weber S, Badr S. The occurrence of sleep-disordered breathing among middle-aged adults. N Engl J Med 1993; 328: 1230-1235.

6. Bitz C, Harder H, Astrup A. A paradoxical diurnal movement pattern in obese subjects with type 2 diabetes. Diabetes Care 2005; 28: 2040-2041.

7. Spiegel K, Leproult R, Van Cauter E. Impact of sleep on metabolic and endocrine function. Lancet 1999; 354: 1435-1439.

8. Fitness Partner's Activity Calculator. URL: http://www.primusweb.com.cgi-bin/fpc/actcalc.pl (accessed 17 July 2005).

9. Medline Plus Medical Encyclopedia. URL: http:// www.nlm.nih.gov/medlineplus/ency/article/001940.htm (accessed 10 July 2005). 